\title{
Características morfogênicas e estruturais de Trachypogon plumosus de acordo com a fertilidade do solo e o nível de desfolha
}

\author{
Newton de Lucena Costa(1), Anibal de Moraes(2), Paulo César de Faccio Carvalho( ${ }^{(3)}$, \\ Alda Lúcia Gomes Monteiro(2) e Ricardo Augusto de Oliveira ${ }^{(2)}$
}

\begin{abstract}
(1)Embrapa Roraima, Rodovia BR 174, Km 8, Distrito Industrial, CEP 69301-970 Boa Vista, RR. E-mail: newton.lucena-costa@embrapa.br (2)Universidade Federal do Paraná, Rua dos Funcionários, o⒈540, CEP 80035-050 Curitiba, PR. E-mail: anibalm@ufpr.br, aldaufpr@gmail.com, rico@ufpr.br (3)Universidade Federal do Rio Grande do Sul, Avenida Bento Gonçalves, № 7.712, CEP 91540-000 Porto Alegre, RS. E-mail: paulocfc@ufrgs.br
\end{abstract}

Resumo - O objetivo deste trabalho foi avaliar os efeitos de estações de crescimento, calagem, adubação e intensidade de desfolha nas características morfogênicas e estruturais de Trachypogon plumosus nos cerrados de Roraima. Foram avaliados os tratamentos: correção da fertilidade do solo (testemunha, calagem, adubação e calagem + adubação), intensidade de desfolha (remoção de 50 e $75 \%$ das folhas) e estações de crescimento (períodos chuvoso e seco). A gramínea respondeu positivamente à correção da fertilidade do solo. A adubação e a calagem + adubação, durante o período chuvoso, proporcionaram maiores taxas de aparecimento de folhas (TApF), taxas de alongamento foliar, número de folhas vivas (NFV), duração de vida de folhas, comprimento final da folha (CFF), índice de área foliar (IAF) e densidade populacional de perfilhos (DPP), além de menor filocrono. As variáveis avaliadas apresentaram redução significativa durante o período seco, exceto a taxa de senescência foliar. A menor intensidade de desfolha afetou positivamente a TApF, o CFF e o IAF, mas não o NFV e a DPP. O manejo com menor intensidade de desfolha maximiza o aproveitamento dos recursos ambientais e a eficiência de utilização da forragem.

Termos para indexação: área foliar, correção do solo, filocrono, manejo, pastagem nativa, perfilhamento.

\section{Morphogenic and structural traits of Trachypogon plumosus according to soil fertility and defoliation level}

\begin{abstract}
The objective of this work was to evaluate the effects of growing seasons, liming, fertilization, and defoliation levels on morphogenetic and structural traits of Trachypogon plumosus in the savanna of the state of Roraima, Brazil. The following treatments were evaluated: correction of soil fertility (control, liming, fertilization, and liming + fertilization), defoliation levels (removal of 50 and $75 \%$ of the leaves), and growing seasons (rainy and dry). The grass positively responded to the correction of soil fertility. Fertilization and liming + fertilization, during the rainy season, provided higher leaf appearance rates (LApR), leaf elongation rates, number of live leaves (NLL), leaf lifespan, final leaf length (FLL), leaf area index (LAI), and tiller population density (TPD), besides a lower phyllochron. The evaluated variables were significantly reduced during the dry season, except for leaf senescence rate. The lowest defoliation level positively affected LApR, FLL, and LAI, but not NLL and TPD. The management with lower defoliation level maximizes the harnessing of environmental resources and forage use efficiency.
\end{abstract}

Index terms: leaf area, soil correction, phyllochron, management, native pasture, tillering.

\section{Introdução}

Nos cerrados de Roraima, as pastagens nativas representam importante recurso forrageiro para alimentação dos rebanhos bovino e ovino. Apesar de limitações quantitativas e qualitativas, decorrentes da baixa fertilidade natural dos solos, essas pastagens proporcionaram, historicamente, o suporte alimentar para a exploração pecuária, que é a principal atividade econômica do estado (Costa et al., 2012b). O pastejo contínuo com taxa de lotação variável, em geral extensivo e desvinculado do ritmo estacional de crescimento das pastagens, contribui diretamente para os baixos índices produtivos dos rebanhos (Baruch et al., 2004). O excesso de lotação animal e a não reposição dos nutrientes extraídos são as principais causas do esgotamento da fertilidade do solo e, consequentemente, da redução da capacidade de suporte e do potencial produtivo das pastagens nativas ao longo dos anos (Sarmiento, 1992). 
Nas áreas planas e não inundáveis dos cerrados, predomina Trachypogon plumosus Ness, gramínea perene, que apresenta hábito de crescimento cespitoso, plantas com 40 a $80 \mathrm{~cm}$ de altura e folhas densamente pilosas. São escassas as informações sobre o potencial produtivo dessa espécie e sobre sua resposta à melhoria das condições ambientais, notadamente quanto à correção da fertilidade do solo e à intensidade de desfolha, o que compromete a proposição de práticas de manejo sustentáveis (Costa et al., 2012a).

$\mathrm{O}$ acúmulo de forragem resulta das alterações morfológicas e fisiológicas que afetam o balanço entre a produção e a senescência de tecidos, com reflexos na composição química, na capacidade de rebrota e na persistência da pastagem (Lemaire et al., 2008). A morfogênese descreve a dinâmica da geração e da expansão da forma da planta no tempo e no espaço. Durante o crescimento vegetativo, a morfogênese de uma gramínea pode ser descrita por três variáveis: taxa de aparecimento, taxa de alongamento e duração de vida das folhas, que, apesar de sua natureza genética, são fortemente influenciadas pelas condições ambientais (temperatura, luz, água e fertilidade do solo) e pelas práticas de manejo. A combinação dessas variáveis condiciona a dinâmica do fluxo de tecidos e as características estruturais da pastagem, que determinam a capacidade de interceptação da radiação solar pelo dossel da pastagem (Pontes et al., 2010). O conhecimento da morfogênese proporciona a visualização da curva estacional de produção de forragem, o que possibilita a estimativa de sua qualidade (Alexandrino et al., 2011) e a proposição de práticas de manejo específicas para cada forrageira (Lemaire et al., 2008).

O objetivo deste trabalho foi avaliar os efeitos de estações de crescimento, calagem, adubação e intensidades de desfolha nas características morfogênicas e estruturais de Trachypogon plumosus nos cerrados de Roraima.

\section{Material e Métodos}

$\mathrm{O}$ experimento foi conduzido em pastagem nativa com predominância de $T$. plumosus, localizada em Boa Vista, Roraima $\left(2^{\circ} 45^{\prime} \mathrm{N}, 60^{\circ} 43^{\prime} \mathrm{W}\right.$, a 93,6 m de altitude), durante o período de julho de 2011 a junho de 2012. Essa pastagem não foi submetida anteriormente a práticas de manejo. O clima da região, segundo a classificação de Köppen, é do tipo Awi, com precipitação anual de $1.600 \mathrm{~mm}$ e temperatura média anual de $28,5^{\circ} \mathrm{C}$. O solo da área experimental é um Latossolo Amarelo, de textura média, com as seguintes características químicas, na profundidade de $0-20 \mathrm{~cm}$ : $\mathrm{pH}\left(\mathrm{H}_{2} \mathrm{O}\right) 5,1 ; 1,1 \mathrm{mg} \mathrm{kg}^{-1}$ de $\mathrm{P} ; 0,51 \mathrm{cmol}_{\mathrm{c}} \mathrm{dm}^{-3} \mathrm{de}$ $\mathrm{Ca}+\mathrm{Mg} ; 0,03 \mathrm{cmol}_{\mathrm{c}} \mathrm{dm}^{-3}$ de K; 0,39 $\mathrm{cmol}_{\mathrm{c}} \mathrm{dm}^{-3} \mathrm{de} \mathrm{Al}$; $2,43 \mathrm{cmol}_{\mathrm{c}} \mathrm{dm}^{-3}$ de $\mathrm{H}+\mathrm{Al}$; SB de $0,54 \mathrm{cmol}_{\mathrm{c}} \mathrm{dm}^{-3}$; e V (\%) de 18,2. Utilizou-se o delineamento experimental de blocos ao acaso com três repetições e arranjo fatorial $4 \times 2 \times 2$, com quatro tratamentos de correção da fertilidade do solo (testemunha, calagem, adubação e calagem + adubação), duas intensidades de desfolha (remoção de 50 e $75 \%$ da parte aérea das plantas, tendose considerado a altura do dossel) e duas estações de crescimento (período chuvoso e seco). A calagem foi realizada 30 dias antes do rebaixamento da pastagem, para elevar a saturação de bases a 40\% (650 kg ha-1 de calcário dolomítico; PRNT $=100 \%$ ). A adubação consistiu de $50 \mathrm{~kg} \mathrm{ha}^{-1}$ de $\mathrm{N}$ (ureia), $50 \mathrm{~kg} \mathrm{ha}^{-1}$ de $\mathrm{P}_{2} \mathrm{O}_{5}$ (superfosfato triplo), $50 \mathrm{~kg} \mathrm{ha}^{-1}$ de $\mathrm{K}_{2} \mathrm{O}$ (cloreto de potássio) e $30 \mathrm{~kg} \mathrm{ha}^{-1}$ de $\mathrm{S}$ (enxofre elementar), aplicados a lanço, após o rebaixamento da pastagem, sem incorporação do corretivo ou dos fertilizantes ao solo.

O rebaixamento da forragem aos níveis de resíduos pré-fixados foi efetuado por ovinos deslanados das raças Morada Nova e Barriga Negra, com idade entre 6 e 12 meses e peso médio de $21 \pm 2,5 \mathrm{~kg}$. A técnica do pastejo em grupo ("mob grazing") foi utilizada para a realização dos pastejos, com duração de 8 a 12 horas, para simular um cenário de lotação intermitente. Os animais entravam na área experimental apenas no momento de pastejo. Foram utilizados 24 piquetes com área individual de $150 \mathrm{~m}^{2}$, os quais foram cercados para contenção dos animais durante o pastejo. Os pastejos foram iniciados quando pelo menos $50 \%$ dos perfilhos por touceira apresentavam três a quatro folhas vivas; para tanto, foram avaliadas dez touceiras por piquete. Medições de altura foram realizadas, durante $o$ transcorrer do pastejo, até que o dossel atingisse cada meta de resíduo estipulada. Após a saída dos animais dos piquetes, foram iniciadas as avaliações de morfogênese, as quais ocorreram nos ciclos de rebrota do período chuvoso - entre julho e agosto de 2011 (624 mm), e entre maio e junho de $2012(277 \mathrm{~mm})$ - e do período seco - de novembro a dezembro de 2011 $(81 \mathrm{~mm})$ e de fevereiro a março de $2012(66 \mathrm{~mm})$.

Para a determinação das características morfogênicas e estruturais, foram selecionadas quatro touceiras por

Pesq. agropec. bras., Brasília, v.48, n.3, p.320-328, mar. 2013 DOI: 10.1590/S0100-204X2013000300011 
piquete e marcados três perfilhos por touceira, com uso de fios coloridos. As avaliações foram realizadas a intervalos de três dias, quando se computava o aparecimento, o alongamento e a senescência de folhas. O número de folhas vivas (NFV) foi obtido pela contagem das folhas verdes não senescentes do perfilho. A taxa de alongamento foliar (TAlF) e a taxa de aparecimento de folhas (TApF) foram calculadas com a divisão do comprimento acumulado de folhas e do número total de folhas no perfilho, respectivamente, pelo período de rebrotação. O comprimento final da folha (CFF) foi determinado pela divisão do alongamento foliar total do perfilho pelo seu número de folhas. A duração de vida das folhas (DFV) foi estimada pela multiplicação do NFV pelo filocrono. Para o cálculo da área foliar, foram coletadas amostras de folhas verdes completamente expandidas e com lígula aparente, até se obter área entre 200 e $300 \mathrm{~cm}^{2}$, estimada com o auxílio de planímetro ótico eletrônico modelo LI-3100C (Li-Cor Biosciences, Lincoln, Nebraska, EUA). Posteriormente, as amostras foram levadas à estufa com circulação forçada de ar, a $65^{\circ} \mathrm{C}$, até atingirem peso constante, para obtenção da massa de matéria seca (MS) foliar. A área foliar específica (AFE) foi determinada por meio da relação entre a área de folhas verdes e a sua MS ( $\mathrm{m}^{2} \mathrm{~g}^{-1} \mathrm{MS}$ foliar). $\mathrm{O}$ índice de área foliar (IAF) foi determinado a partir do produto da MS total das folhas verdes ( $\mathrm{g} \mathrm{m}^{-2}$ de $\mathrm{MS}$ ) pela AFE $\left(\mathrm{m}^{2} \mathrm{~g}^{-1}\right.$ de MS foliar). A taxa de senescência foliar (TSF) foi obtida com a divisão do comprimento das folhas com coloração amarelada ou necrosada, pela idade de rebrota. A densidade populacional de perfilhos (DPP) foi estimada com o uso de armações metálicas de $0,25 \mathrm{~m}^{2}(50 \times 50 \mathrm{~cm})$, alocadas em quatro pontos ao acaso em cada parcela, tendo sido computados todos os perfilhos vivos, em cada período de avaliação. O filocrono foi determinado como o inverso do coeficiente angular da regressão entre o número de folhas e a soma térmica (graus-dia, GD). Para o cálculo do acúmulo de GD, utilizou-se a fórmula: $\left.\mathrm{GD}=\left[\left(\mathrm{T}_{\text {Máx. }}+\mathrm{T}_{\text {Mín. }}\right) / 2\right)\right]-\mathrm{T}_{\mathrm{b}}$, em que $\mathrm{T}_{\text {Máx. é a }}$ temperatura máxima do ar $\left({ }^{\circ} \mathrm{C}\right) ; \mathrm{T}_{\text {Min. }}$ é a temperatura mínima do ar $\left({ }^{\circ} \mathrm{C}\right)$; e $\mathrm{T}_{\mathrm{b}}$ é a temperatura mínima basal da planta $\left(10^{\circ} \mathrm{C}\right)$. Os dados foram submetidos à análise de variância, e as médias foram comparadas pelo teste de Tukey, a 5\% de probabilidade, com uso do programa Sisvar.

\section{Resultados e Discussão}

A taxa de aparecimento foliar e o filocrono foram afetados pelos tratamentos de correção da fertilidade do solo e estações de crescimento (Tabela 1). As maiores $\mathrm{TApF}$ foram registradas no período chuvoso e com a aplicação de adubação ( 0,156 folha por perfilho por dia) ou de calagem + adubação $(0,151$ folha por perfilho por dia). Na ausência de limitações hídricas e nutricionais, a planta produz folhas a um ritmo determinado geneticamente, em função direta da temperatura (Lemaire et al., 2008). A redução da TApF, durante o período seco, decorre da baixa disponibilidade de água no solo, a qual afeta diretamente a multiplicação e o alongamento celular, com reflexos negativos sobre os processos bioquímicos (fotossíntese e respiração) e físicos (transpiração e evaporação) (Pontes et al., 2010). O decréscimo na TApF para os tratamentos testemunha, calagem, adubação e calagem + adubação foi de 14,2, 8,4, 17,9 e 3,9\%, respectivamente. Costa et al. (2012b) registraram decréscimo de 35,7\% na TApF de $T$. plumosus, durante o período seco ( 0,09 folha por perfilho por dia), quando comparado ao chuvoso $(0,14$ folha por perfilho por dia).

A TApF não foi afetada pela intensidade de desfolha, o que pode ser explicado como um mecanismo compensatório decorrente de maiores densidade de perfilhos e comprimento final das folhas, uma vez que o número de folhas vivas apresenta forte componente genético e é relativamente constante para uma determinada espécie, sob condições semelhantes de manejo (Lemaire et al., 2008). Em outras espécies de gramíneas, como Urochloa brizantha 'Xaraés' (Syn. Brachiaria brizantha) (Lara \& Pedreira, 2011) e U. decumbens (syn. B. decumbens) (Da Silva et al.,

Tabela 1. Taxa de aparecimento de folhas e filocrono de Trachypogon plumosus, de acordo com as estações de crescimento e em reposta à calagem e à adubação ${ }^{(1)}$.

\begin{tabular}{lcccc}
\hline $\begin{array}{l}\text { Estação de } \\
\text { crescimento }\end{array}$ & Testemunha & Calagem & Adubação & $\begin{array}{c}\text { Calagem + } \\
\text { Adubação }\end{array}$ \\
\hline \multicolumn{5}{c}{ Taxa de aparecimento de folhas (folha por perfilho por dia) } \\
Período chuvoso & $0,126 \mathrm{Ca}$ & $0,142 \mathrm{Ba}$ & $0,156 \mathrm{Aa}$ & $0,151 \mathrm{Aa}$ \\
Período seco & $0,108 \mathrm{Cb}$ & $0,130 \mathrm{Ba}$ & $0,128 \mathrm{Bb}$ & $0,145 \mathrm{Aa}$ \\
\hline \multicolumn{5}{c}{ Filocrono (graus-dia por folha) } \\
Período chuvoso & $274,7 \mathrm{Ab}$ & $227,7 \mathrm{Ba}$ & $201,2 \mathrm{Ba}$ & $203,3 \mathrm{Bb}$ \\
Período seco & $297,1 \mathrm{Aa}$ & $242,8 \mathrm{Ba}$ & $221,3 \mathrm{Ca}$ & $227,0 \mathrm{Ca}$ \\
\hline
\end{tabular}

${ }^{(1)}$ Médias seguidas de letras iguais, maiúsculas nas linhas e minúsculas nas colunas, não diferem pelo teste de Tukey, a 5\% de probabilidade. 
2012), as TApF não foram influenciadas pelo nível de desfolha (20 e $50 \mathrm{~cm})$.

A TApF é a principal característica morfogênica de forrageiras, pois afeta diretamente os componentes estruturais da pastagem (CFF, DPP e NFV) e, mesmo sob condições ambientais ou de manejo desfavoráveis, ela é a última a ser afetada, ou seja, para manter o desenvolvimento do perfilho em condições limitantes de carbono, a economia de fotoassimilados se iniciaria pela redução da densidade de perfilhos, seguida por decréscimos no comprimento e na duração das folhas (Lemaire et al., 2008). A TApF resulta do balanço entre o comprimento da bainha que envolve o meristema apical e a taxa de alongamento foliar, as quais, respectivamente, determinam a distância que a folha tem de percorrer para emergir e a velocidade com que ela percorre essa distância (Pontes et al., 2010). As taxas de aparecimento e alongamento foliar podem estar negativamente correlacionadas. Assim, quanto maior for a TApF, menor seria o tempo disponível para o alongamento das folhas, o que afetaria diretamente o comprimento final das folhas (Lemaire et al., 2008). No presente trabalho, as correlações da TApF com a taxa de alongamento foliar $(\mathrm{r}=0,9017 ; \mathrm{p}=0,0022)$ e $\mathrm{o}$ comprimento final das folhas $(\mathrm{r}=0,8956 ; \mathrm{p}=0,0018)$ foram positivas e significativas. Em pastagens de $U$. decumbens sob lotação contínua e com altura fixa ou variável do dossel durante as estações do ano, Santos et al. (2012) também constataram correlações positivas e altamente significativas entre essas variáveis.

Os filocronos foram reduzidos pelos tratamentos de correção da fertilidade do solo (Tabela 1), e os menores valores foram observados durante o período chuvoso nos tratamentos adubação (201,2 GD por folha) e calagem + adubação (203,3 GD por folha). Quanto menor o filocrono, mais eficiente é a gramínea na interceptação e na conversão de energia luminosa em tecido foliar (Lemaire et al., 2008). O filocrono aumenta com a idade da planta, em razão do maior tempo para a folha percorrer a distância entre o meristema apical e a extremidade do pseudocolmo formado pelas bainhas das folhas mais velhas (Difante et al., 2011). Durante o período seco, T. plumosus demandou maior tempo térmico para a emissão de uma nova folha, em consequência da baixa disponibilidade hídrica do solo. O período seco foi responsável por incrementos de $8,2,6,6,9,9$ e $11,7 \%$ no filocrono dos tratamentos testemunha, calagem, adubação e calagem + adubação, respectivamente. Em trabalho com T. plumosus, Costa et al. (2012b) relataram acréscimo de 32,4\% no filocrono durante o período seco (10,5 dias por folha), comparativamente ao chuvoso (7,1 dias por folha).

A taxa de alongamento foliar e o número de folhas vivas foram influenciados pelas estações de crescimento, pela correção da fertilidade do solo e pela intensidade de desfolha (Tabela 2). As maiores taxas de alongamento foram registradas com calagem + adubação (1,722 e 1,613 cm por dia por perfilho, respectivamente, para 50 e $75 \%$ de desfolha) ou com adubação apenas, com baixa intensidade de desfolha (1,603 cm por dia por perfilho). Esses valores foram superiores aos relatados por Baruch et al. (2004) para T. plumosus submetido a frequências de corte de 7 $(0,70 \mathrm{~cm}$ por dia por perfilho), $14(0,91 \mathrm{~cm}$ por dia por perfilho) ou 28 dias (1,57 cm por dia por perfilho). A taxa de alongamento foliar responde ao suprimento de nutrientes e atua como agente modificador da TApF, notadamente com a emissão de folhas sucessivas em níveis de inserção mais próximos (Pontes et al., 2010). Além disso, essa taxa é a variável morfogênica mais correlacionada, isoladamente, ao rendimento de matéria seca. Portanto, ela é um estimador adequado do vigor de rebrota, uma vez que determina, juntamente com a TApF, o tamanho da superfície fotossintetizante do dossel, de forma direta por meio de sua influência no comprimentofinal das folhas, e indireta, pelo efeito sobre a densidade de perfilhos (Lemaire et al., 2008). Apesar da sua natureza genética, a taxa de alongamento foliar responde diferenciadamente às condições ambientais,

Tabela 2. Taxa de alongamento foliar (TAIF) e número de folhas vivas de Trachypogon plumosus, de acordo com as estações de crescimento e em resposta às intensidades de desfolha, à calagem e à adubação ${ }^{(1)}$.

\begin{tabular}{lccccc}
\hline $\begin{array}{l}\text { Estação de } \\
\text { crescimento }\end{array}$ & $\begin{array}{c}\text { Desfolha } \\
(\%)\end{array}$ & Testemunha & Calagem & $\begin{array}{r}\text { Adubação } \\
\text { Calagem + } \\
\text { Adubação }\end{array}$ \\
\hline \multicolumn{5}{c}{ TAIF (cm por dia por perfilho) } \\
Período & 50 & $0,995 \mathrm{Ca}$ & $1,366 \mathrm{Ba}$ & $1,603 \mathrm{Aa}$ & $1,722 \mathrm{Aa}$ \\
chuvoso & 75 & $0,816 \mathrm{Cb}$ & $1,243 \mathrm{Bab}$ & $1,451 \mathrm{Ab}$ & $1,613 \mathrm{Aa}$ \\
Período & 50 & $0,725 \mathrm{Cb}$ & $1,098 \mathrm{Bb}$ & $1,379 \mathrm{Ab}$ & $1,458 \mathrm{Ab}$ \\
seco & 75 & $0,731 \mathrm{Cb}$ & $1,181 \mathrm{Bb}$ & $1,305 \mathrm{Ab}$ & $1,434 \mathrm{Ab}$ \\
\hline \multicolumn{5}{c}{ Número de folhas vivas (folhas por perfilho) } \\
Período & 50 & $3,29 \mathrm{Cb}$ & $4,45 \mathrm{Bb}$ & $4,82 \mathrm{Ab}$ & $4,93 \mathrm{Ab}$ \\
chuvoso & 75 & $3,86 \mathrm{Ca}$ & $4,78 \mathrm{Ba}$ & $4,98 \mathrm{Aa}$ & $5,12 \mathrm{Aa}$ \\
Período & 50 & $3,06 \mathrm{Cb}$ & $4,14 \mathrm{Bc}$ & $4,54 \mathrm{Ad}$ & $4,68 \mathrm{Ab}$ \\
seco & 75 & $3,18 \mathrm{Bb}$ & $4,65 \mathrm{Aa}$ & $4,78 \mathrm{Ac}$ & $4,72 \mathrm{Ab}$ \\
\hline
\end{tabular}

${ }^{(1)}$ Médias seguidas de letras iguais, maiúsculas nas linhas e minúsculas nas colunas, não diferem pelo teste de Tukey, a 5\% de probabilidade. 
principalmente temperatura, disponibilidade hídrica, fertilidade do solo e luminosidade (Pontes et al., 2010). Santos et al. (2012), ao avaliar U. brizantha, observaram que o alongamento foliar, a TApF e o comprimento das folhas correlacionaram-se positivamente com o número de folhas vivas remanescentes no perfilho após a desfolha. O tamanho do perfilho, de forma esperada, esteve fortemente correlacionado com a duração e com a taxa de alongamento foliar. $\mathrm{O}$ aumento da taxa de alongamento pelo suprimento de nutrientes não tem efeito no tamanho final da célula ou na taxa de alongamento da célula epidérmica (Difante et al., 2011), e decorre unicamente da intensificação da divisão foliar. As taxas de alongamento, independentemente da intensidade de desfolha, foram menores durante o período seco, com reduções de 19,6, 12,6, 12,1 e 13,3\%, para os tratamentos testemunha, calagem, adubação e calagem + adubação, respectivamente (Tabela 2). Costa et al. (2012b) registraram decréscimo de 67,3\% na taxa de alongamento foliar de T. plumosus, durante o período seco $(0,54 \mathrm{~cm}$ por dia por perfilho), em comparação ao chuvoso (1,65 cm por dia por perfilho).

Durante o período seco, a taxa de alongamento foliar não foi afetada pela intensidade de desfolha, enquanto, no período chuvoso, maiores valores foram observados com desfolha de $50 \%$, exceto nos tratamento calagem + adubação ou calagem, nos quais ela não teve efeito significativo (Tabela 2). A menor intensidade de desfolha proporciona retenção de maior área foliar, o que acarreta maior velocidade inicial de rebrota e menor tempo para que a gramínea atinja a máxima eficiência fotossintética, bem como menor remobilização de reservas orgânicas para o novo crescimento. A maior quantidade de material foliar retido sob desfolhas menos intensas permite maior remobilização de nutrientes para as folhas em alongamento (Lemaire et al., 2008). Baruch \& Jackson (2005) relataram maiores taxas de alongamento em pastagens de $T$. plumosus mantidas com resíduo de $30 \mathrm{~cm}(0,9 \mathrm{~cm}$ por dia por perfilho) do que com $10 \mathrm{~cm}$ $(0,5 \mathrm{~cm}$ por dia por perfilho).

O número de folhas vivas respondeu positivamente à melhoria da fertilidade do solo. Os maiores valores foram verificados durante o período chuvoso com calagem + adubação (5,03 folhas por perfilho) ou com adubação (4,90 folhas por perfilho), tendo sido semelhantes entre si, mas superiores à calagem $(4,62$ folhas por perfilho) e à testemunha $(3,58$ folhas por perfilho) (Tabela 2). As plantas adubadas atingiram máximo de folhas vivas mais precocemente que as não adubadas, o que possibilitou colheitas mais frequentes, a fim de evitar perdas por senescência foliar. Costa et al. (2011) constataram máximos número de folhas vivas durante o período chuvoso, em $T$. vestitus, com períodos de descanso entre 49 e 56 dias. O número de folhas vivas, por ser uma característica estrutural com forte influência genética, estável na ausência de deficiências hídricas ou nutricionais e constante a partir do momento em que a taxa de senecência se iguala à $\mathrm{TApF}$, constitui critério objetivo e prático para a definição dos períodos de descanso, na lotação rotacionada, e da intensidade de pastejo, na lotação contínua. Neste contexto, a presença de quatro a cinco folhas vivas por perfilho indicaria o momento adequado para o início do pastejo em pastagens de T. plumosus, para se obter forragem com melhor valor nutritivo e reduzir as perdas por senescência.

$\mathrm{O}$ número de folhas vivas, durante o período seco, diminuiu em $12,8,4,9,5,0$ e $6,4 \%$, nos tratamentos testemunha, calagem, adubação e calagem + adubação, respectivamente. Costa et al. $(2011,2012$ a) relataram, para $T$. vestitus, decréscimo de $21,5 \%$ nessa variável durante o período seco ( 5,1 folhas por perfilho), em comparação com período chuvoso (6,5 folhas por perfilho). A maior intensidade de desfolha resultou em maior número de folhas vivas: 3,52, 4,72, 4,88 e 4,92 folhas por perfilho, para testemunha, calagem, adubação e calagem + adubação, respectivamente (Tabela 2). A desfolha induz modificações na quantidade e na qualidade da luz que chega às folhas mais próximas do solo, que podem proporcionar ambiente mais favorável à manutenção de maior número de folhas, mas que foram insuficientes para estabelecer uma correlação positiva com a TApF, o comprimento foliar ou a duração das folhas (Pontes et al., 2003). Santos et al. (2012), em U. decumbens, e Lara \& Pedreira (2011), em U. brizantha 'Marandu', encontraram maior número de folhas vivas com níveis de desfolha de 10 e 7,5 cm (5,24 e 5,70 folhas por perfilho), respectivamente, do que com níveis de 50 e $15 \mathrm{~cm}(4,28$ e 5,10 folhas por perfilho).

A duração de vida das folhas foi afetada pelas estações de crescimento e pela correção da fertilidade do solo, com os maiores valores observados durante o período chuvoso, com adubação (38,1 dias por folha) ou com calagem + adubação (35 dias por folha) 
(Tabela 3). Essa variável representa uma característica morfogênica importante na determinação do fluxo de tecidos, pois indica o máximo potencial de rendimento de forragem (máxima quantidade de material vivo por área); além disso, é um parâmetro para a determinação da intensidade de pastejo com lotação contínua, ou da frequência entre pastejos na lotação rotacionada, que assegura a manutenção do IAF em valores próximos aos necessários para a maior eficiência de interceptação da radiação incidente e para taxas de crescimento máximas.

A duração das folhas, durante o período seco, diminuiu em $12,4,5,3,15,5$ e $10,8 \%$, para testemunha, calagem, adubação e calagem + adubação, respectivamente (Tabela 3). As folhas apresentam tempo de vida limitado, o qual é determinado por características genéticas e influenciado por fatores ambientais e práticas de manejo. A longevidade das folhas, durante o período chuvoso, é consequência da dinâmica de renovação de tecidos, em decorrência de maiores taxas de crescimento e de fixação de carbono, e a diminuição dessa longevidade constitui estratégia de absorção de nutrientes em períodos favoráveis e de sua conservação para utilização quando em condições ambientais adversas (Lemaire et al., 2008). Magalhães (2010) constatou acréscimo de 9,8\% na duração de vida das folhas de Andropogon gayanus 'Planaltina' ao aumentar a reposição da lâmina de água evaporada do Tanque Classe A de 50\% (24,81 dias por folha) para $80 \%$ (27,25 dias por folha).

Os maiores comprimentos de folha foram registrados durante o período chuvoso com $50 \%$ de desfolha e uso de calagem + adubação $(18,2 \mathrm{~cm})$ ou de adubação $(17,3 \mathrm{~cm})$ (Tabela 4$)$. O estímulo à divisão celular, quando as condições para o crescimento são favoráveis e constantes, possibilita a obtenção de lâminas maiores para um mesmo comprimento de bainha (Ferraro \& Oesterheld, 2002; Pontes et al., 2010). A adubação, ao estimular a produção de novas

Tabela 3. Duração de vida de folhas (dias por folha) de Trachypogon plumosus, de acordo com as estações de crescimento e em resposta à calagem e à adubação ${ }^{(1)}$.

\begin{tabular}{lcccc}
\hline $\begin{array}{l}\text { Estação de } \\
\text { crescimento }\end{array}$ & Testemunha & Calagem & Adubação & $\begin{array}{c}\text { Calagem }+ \\
\text { Adubação }\end{array}$ \\
\hline $\begin{array}{l}\text { Período chuvoso } \\
\text { Período seco }\end{array}$ & $32,8 \mathrm{Ba}$ & $33,9 \mathrm{Ba}$ & $38,1 \mathrm{Aa}$ & $35,0 \mathrm{ABa}$ \\
\hline
\end{tabular}

${ }^{(1)}$ Médias seguidas de letras iguais, maiúsculas nas linhas e minúsculas nas colunas, não diferem pelo teste de Tukey, a $5 \%$ de probabilidade. células, possibilita aumento na taxa de alongamento, o que constitui estratégia para alteração no comprimento foliar (Garcez Neto et al., 2002). A divisão celular é o principal mecanismo de crescimento da lâmina foliar, contrariamente ao da bainha que resulta do alongamento celular (Lemaire et al., 2008). O comprimento final de folhas e o ângulo de inserção destas interferem na distribuição e na qualidade da luz dentro do dossel, o que afeta a modulação do crescimento das plantas por meio da produção de fotoassimilados nas fontes e da sua alocação aos drenos (Difante et al., 2011). As folhas de $T$. plumosus apresentam ângulo de inserção entre 45 e $60^{\circ}$ e coeficiente de extinção luminosa entre 0,52 e 0,65 . Isso facilita a penetração da radiação vermelha em detrimento da vermelha-extremo, o que, por sua vez, acarreta melhor qualidade de luz para a fotossíntese das folhas situadas na porção inferior da planta e contribui para o retardamento ou a atenuação do processo de senescência (Baruch et al., 2004).

O comprimento final de folhas, durante o período seco, diminuiu em 8,6, 8,2, 7,4 e 7,5\%, para testemunha, calagem, adubação e calagem + adubação, respectivamente (Tabela 4). Simoes \& Baruch (1991) estimaram, em T. plumosus, decréscimos de 63,9 e $71,4 \%$ nesta variável durante o período seco $(9,2$ e $13,4 \mathrm{~cm})$, em comparação ao período chuvoso $(25,5$ e $46,8 \mathrm{~cm}$ ), para pastagens submetidas a períodos de descanso de 14 e 28 dias, respectivamente. A redução do comprimento foliar é um meio utilizado pelas gramíneas nativas dos cerrados para conservação de água, por meio da diminuição das perdas de água por transpiração (Baruch et al., 2004). Os fatores determinantes do comprimento final de folhas são as taxas de aparecimento e de alongamento foliar. Observou-se correlação positiva do comprimento final de folhas com as taxas de alongamento $(\mathrm{r}=0,7984 ; \mathrm{p}=0,0015)$ e de aparecimento de folhas

Tabela 4. Comprimento final de folhas (cm) de Trachypogon plumosus com as estações de crescimento e em resposta às intensidades de desfolhação, à calagem e à adubação ${ }^{(1)}$.

\begin{tabular}{lccccc}
\hline $\begin{array}{l}\text { Estação de } \\
\text { crescimento }\end{array}$ & $\begin{array}{c}\text { Desfolha } \\
(\%)\end{array}$ & Testemunha & Calagem & Adubação & $\begin{array}{c}\text { Calagem }+ \\
\text { Adubação }\end{array}$ \\
\hline Período & 50 & $15,7 \mathrm{Ba}$ & $15,9 \mathrm{Ba}$ & $17,3 \mathrm{Aa}$ & $18,2 \mathrm{Aa}$ \\
chuvoso & 75 & $10,9 \mathrm{Dc}$ & $13,5 \mathrm{Cb}$ & $15,2 \mathrm{Bbc}$ & $16,4 \mathrm{Ab}$ \\
Período & 50 & $12,3 \mathrm{Cb}$ & $13,8 \mathrm{Bb}$ & $15,8 \mathrm{Ab}$ & $16,2 \mathrm{Ab}$ \\
seco & 75 & $11,9 \mathrm{Cbc}$ & $13,2 \mathrm{Bb}$ & $14,2 \mathrm{Bc}$ & $15,8 \mathrm{Ab}$ \\
\hline
\end{tabular}

${ }^{(1)}$ Médias seguidas de letras iguais, maiúsculas nas linhas e minúsculas nas colunas, não diferem pelo teste de Tukey, a $5 \%$ de probabilidade. 
$(\mathrm{r}=0,8826 ; \mathrm{p}=0,0002)$. A altura da bainha é outro fator importante, pois define a extensão da zona de crescimento a ser percorrida pela lâmina em expansão (Ferraro \& Oesterheld, 2002). Em T. plumosus, Sarmiento (1992) constatou acréscimo de $1,76 \mathrm{~cm}$ no comprimento final de folhas para cada centímetro de altura da bainha.

O comprimento final de folhas foi inversamente proporcional ao nível de desfolha, com reduções de $18,8,10,1,11,4$ e $6,4 \%$, para testemunha, calagem, adubação e calagem + adubação, respectivamente (Tabela 4). O primeiro efeito da desfolha é uma resposta plástica da planta para adaptação às modificações em seu ambiente, e, por meio do mecanismo de escape, ocorrem adaptações morfogênicas e arquiteturais que reduzem a acessibilidade das folhas ao pastejo, como redução do comprimento das folhas e da altura das plantas, além do hábito de crescimento prostrado. Na maior intensidade de desfolha, a competição por luz é atenuada pela maior remoção da área foliar; contudo, nessa condição, as plantas tendem a desenvolver folhas mais curtas (Pontes et al., 2010). Baruch \& Jackson (2005) estimaram maiores comprimento de folhas em pastagens de $T$. plumosus mantidas com resíduo de $30 \mathrm{~cm}(12,7 \mathrm{~cm})$ do que com $10 \mathrm{~cm}(7,1 \mathrm{~cm})$.

O IAF foi influenciado por estações de crescimento, intensidade de desfolha e correção da fertilidade do solo (Tabela 5). Os maiores valores foram obtidos durante o período chuvoso com $50 \%$ de desfolha e aplicação de calagem + adubação $(3,21)$ ou com adubação $(3,07)$, que foram semelhantes entre si e superiores aos registrados com calagem $(1,98)$ ou testemunha $(1,47)$. O IAF foi positivamente correlacionado com as taxas de aparecimento $(\mathrm{r}=0,8345 ; \mathrm{p}=0,0022)$ e alongamento foliar $(\mathrm{r}=0,9455 ; \mathrm{p}=0,0035)$, e com o comprimento final de folhas $(\mathrm{r}=0,8888 ; \mathrm{p}=0,0001)$, o que evidencia a sincronia entre essas três variáveis. As gramíneas apresentam natureza dinâmica de crescimento e buscam, de forma consistente, por meio de alterações em sua forma e função, a manutenção de uma área mínima fotossinteticamente ativa (Pontes et al., 2010). Gramíneas com maior habilidade competitiva desenvolvem arquitetura foliar mais eficiente para a interceptação de luz, em decorrência do alongamento da bainha e dos entrenós do colmo e, consequentemente da maior altura das plantas (Pontes et al., 2003). A ação positiva da melhoria da fertilidade do solo sobre o alongamento foliar, o comprimento de folhas e a densidade populacional de perfilhos se expressa diretamente sobre o IAF da pastagem (Pontes et al., 2010). Em gramíneas de hábito de crescimento cespitoso, o IAF crítico, em que $95 \%$ da luz incidente é interceptada, normalmente varia entre 3,0 e 5,0 (Sarmiento, 1992), condição que foi atendida apenas durante o período chuvoso e com o uso de adubação ou de calagem + adubação.

Tabela 5. Índice de área foliar, densidade populacional de perfilhos e taxa de senescência foliar de Trachypogon plumosus, de acordo com as estações de crescimento e em resposta às intensidades de desfolha, à calagem e à adubação ${ }^{(1)}$.

\begin{tabular}{|c|c|c|c|c|c|}
\hline $\begin{array}{l}\text { Estação de } \\
\text { crescimento }\end{array}$ & $\begin{array}{c}\text { Desfolha } \\
(\%)\end{array}$ & Testemunha & Calagem & Adubação & $\begin{array}{l}\text { Calagem + } \\
\text { Adubação }\end{array}$ \\
\hline & & \multicolumn{4}{|c|}{ Índice de área foliar } \\
\hline \multirow[t]{2}{*}{ Período chuvoso } & 50 & $1,47 \mathrm{Ca}$ & $1,98 \mathrm{Ba}$ & $3,07 \mathrm{Aa}$ & $3,21 \mathrm{Aa}$ \\
\hline & 75 & $1,13 \mathrm{Dbc}$ & $1,62 \mathrm{Cb}$ & $2,33 \mathrm{Bb}$ & $2,58 \mathrm{Abc}$ \\
\hline \multirow[t]{3}{*}{ Período seco } & 50 & $1,33 \mathrm{Dab}$ & $1,76 \mathrm{Cb}$ & $2,42 \mathrm{Bb}$ & $2,63 \mathrm{Ab}$ \\
\hline & 75 & $1,05 \mathrm{Cc}$ & $1,49 \mathrm{Bc}$ & $2,27 \mathrm{Ab}$ & 2,39Ac \\
\hline & & \multicolumn{4}{|c|}{ Densidade populacional de perfilhos (perfilhos por metro quadrado) } \\
\hline \multirow[t]{2}{*}{ Período chuvoso } & 50 & $501 \mathrm{Cbc}$ & 633Bab & $743 \mathrm{Ab}$ & $788 \mathrm{Ab}$ \\
\hline & 75 & $586 \mathrm{Ca}$ & $679 \mathrm{Ba}$ & 848Aa & $859 \mathrm{Aa}$ \\
\hline \multirow[t]{3}{*}{ Período seco } & 50 & $411 \mathrm{Cd}$ & $530 \mathrm{Bc}$ & $621 \mathrm{Ac}$ & $655 \mathrm{Ac}$ \\
\hline & 75 & $477 \mathrm{Ccd}$ & $598 \mathrm{Bbc}$ & $708 \mathrm{Ab}$ & $737 \mathrm{Ab}$ \\
\hline & & \multicolumn{4}{|c|}{ Taxa de senescência foliar (cm por dia por perfilho) } \\
\hline \multirow[t]{2}{*}{ Período chuvoso } & 50 & $0,143 \mathrm{Cbc}$ & $0,168 \mathrm{Bc}$ & $0,191 \mathrm{Ac}$ & $0,198 \mathrm{Ac}$ \\
\hline & 75 & $0,134 \mathrm{Cc}$ & $0,156 \mathrm{Bc}$ & $0,182 \mathrm{Ac}$ & $0,191 \mathrm{Ac}$ \\
\hline \multirow[t]{2}{*}{ Período seco } & 50 & $0,174 \mathrm{Ca}$ & $0,211 \mathrm{Ba}$ & $0,248 \mathrm{Aa}$ & $0,263 \mathrm{Aa}$ \\
\hline & 75 & 0,159Dab & $0,187 \mathrm{Cb}$ & $0,207 \mathrm{Bb}$ & $0,231 \mathrm{Ab}$ \\
\hline
\end{tabular}

${ }^{(1)}$ Médias seguidas de letras iguais, maiúsculas nas linhas e minúsculas nas colunas, não diferem pelo teste de Tukey, a $5 \%$ de probabilidade. 
$\mathrm{O}$ aumento da intensidade de desfolha resultou em decréscimos de $22,1,16,6,16,0$ e $14,9 \%$ do IAF, para testemunha, calagem, adubação e calagem + adubação, respectivamente (Tabela 5). O IAF representa a síntese das características morfogênicas e estruturais da gramínea, e é consequência do balanço entre processos que determinam a oferta (fotossíntese) e a demanda (respiração, acúmulo de reservas, síntese e senescência de tecidos) dos fotoassimilados, que estabelecem o ritmo de crescimento da pastagem (Pontes et al., 2010). Independentemente da intensidade de desfolha, o IAF, durante o período seco, diminuiu em 8,5, 10,0, 13,3 e $13,4 \%$, para testemunha, calagem, adubação e calagem + adubação, respectivamente (Tabela 5). Esse resultado foi consequência das menores taxas de crescimento e maiores de senescência foliar, ocasionadas pela baixa disponibilidade de água no solo. Costa et al. $(2011,2012 a)$ relataram reduções de 52,6 e 48,9\% na área foliar de $T$. vestitus, durante o período seco, quando comparado ao chuvoso, em pastagens submetidas a períodos de descanso de 42 (62,3 vs. $29,5 \mathrm{~cm}^{2}$ por perfilho) e 56 dias $(83,1$ vs. $42,4 \mathrm{~cm}^{2}$ por perfilho), respectivamente.

A densidade populacional de perfilhos foi influenciada por estações de crescimento, intensidade de desfolha e correção da fertilidade do solo (Tabela 5). Os maiores valores foram obtidos durante o período chuvoso com $75 \%$ de desfolha e aplicação de calagem + adubação (859 perfilhos por metro quadrado) e com adubação (848 perfilhos por metro quadrado). Esses valores foram semelhantes entre si e superiores aos estimados com calagem (679 perfilhos por metro quadrado) ou na testemunha (586 perfilhos metro quadrado). O perfilhamento é consequência da velocidade de emissão de folhas, as quais, dependendo das condições ambientais e das práticas de manejo, produzirão gemas potencialmente capazes de originar novos perfilhos (Lemaire et al., 2008). Além disso, o perfilhamento estabelece gradativamente uma condição de limitação à penetração de luz, com sombreamento das folhas inferiores que favorece a senescência foliar. $O$ sombreamento reduz a proporção de gemas que efetivamente se transformarão em novos perfilhos, com reflexos negativos e diretos na densidade de perfilhos, no número de folhas vivas e na $\mathrm{TApF}$, e indiretos na taxa de alongamento foliar e no comprimento final de folhas (Alexandrino et al.,
2011). A DPP, durante o período seco, diminuiu em $17,4,14,0,16,6$ e 15,5\%, para testemunha, calagem, adubação e calagem + adubação, respectivamente. Costa et al. (2011, 2012a) relataram decréscimo de $30,4 \%$ na DPP de $T$. vestitus, durante o período seco (224 perfilhos por metro quadrado), comparativamente ao chuvoso (322 perfilhos por metro quadrado).

As maiores taxas de senescência foliar foram observadas durante o período seco, com de $50 \%$ de desfolha e na presença de calagem + adubação $(0,263 \mathrm{~cm}$ por dia por perfilho) ou de adubação $(0,231 \mathrm{~cm}$ por dia por perfilho), enquanto a menor foi observada na testemunha, durante o período chuvoso, independentemente do nível de desfolha $(0,139 \mathrm{~cm}$ por dia por perfilho) (Tabela 5). Na ausência de adubação, as plantas permanecem mais tempo com suas folhas vivas, em detrimento do aparecimento ou da expansão das folhas, o que contribui para o retardamento do processo de senescência.

Quando o perfilho atinge determinado número de folhas vivas, ocorre equilíbrio entre a TApF e a senescência das folhas, de modo que o surgimento de nova folha acarreta senescência da folha que a precedeu, o que tende a manter o número de folhas vivas relativamente constante (Difante et al., 2011). Apesar do efeito negativo sobre a qualidade da forragem, a senescência representa um importante processo fisiológico no fluxo de tecidos da gramínea. Silva \& Haridasan (2007), que trabalharam com diversas gramíneas nativas do cerrado, estimaram eficiências de remobilização das folhas senescentes, para a produção de novos tecidos foliares, de 34,9, $68,4,86,9$ e 42,2\%, respectivamente, para N, P, K e Mg.

\section{Conclusões}

1. Trachypogon plumosus responde positivamente à melhoria da fertilidade do solo.

2. As estações de crescimento, a correção da fertilidade do solo e a intensidade de desfolha afetam o padrão de acúmulo de forragem e as características morfogênicas e estruturais de T. plumosus, e o manejo com menor intensidade de desfolha aumenta $o$ aproveitamento dos recursos ambientais e a eficiência de utilização da forragem.

3. A correção da fertilidade do solo tem maior influência sobre a morfogênese de T. plumosus do que a intensidade de desfolha. 


\section{Referências}

ALEXANDRINO, E.; CÂNDIDO, M.J.D.; GOMIDE, J.A. Fluxo de biomassa e taxa de acúmulo de forragem em capim Mombaça mantido sob diferentes alturas. Revista Brasileira de Saúde e Produção Animal, v.12, p.59-71, 2011.

BARUCH, Z.; JACKSON, R.B. Responses of tropical native and invader $\mathrm{C}_{4}$ grasses to water stress, clipping and increased atmospheric $\mathrm{CO}_{2}$ concentration. Oecologia, v.145, p.522-532, 2005. DOI: $10.1007 / \mathrm{s} 00442-005-0153-\mathrm{x}$.

BARUCH, Z.; NASSAR, J.M.; BUBIS, J. Quantitative trait, genetic, environmental, and geographical distances among populations of the $\mathrm{C}_{4}$ grass Trachypogon plumosus in Neotropical savannas. Diversity and Distributions, v.10, p.283-292, 2004. DOI: 10.1111/j.1366-9516.2004.00102.x.

COSTA, N. de L.; GIANLUPPI, V.; MORAES, A. de. Morfogênese de Trachypogon vestitus submetido à queima, durante o período seco, nos cerrados de Roraima. Ciência Animal Brasileira, v.13, p.41-48, 2012a. DOI: 10.5216/cab.v13i1.12803.

COSTA, N. de L.; GIANLUPPI, V.; MORAES, A. de. Produtividade de forragem e morfogênese de Trachypogon vestitus em diferentes idades de rebrota nos cerrados de Roraima. Revista Brasileira de Saúde e Produção animal, v.12, p.935-948, 2011.

COSTA, N. de L.; MORAES, A. de; GIANLUPPI, V.; BENDAHAN, A.B.; MAGALHÃES, J.A. Acúmulo de forragem e características morfogênicas e estruturais de Trachypogon plumosus, durante o período seco, nos cerrados de Roraima. Bioscience Journal, v.28, p.515-526, 2012b.

DA SILVA, T.C.; PERAZZO, A.F.; MACEDO, C.H.O.; BATISTA, E.D.; PINHO, R.M.A.; BEZERRA, H.F.C.; SANTOS, E.M. Morfogênese e estrutura de Brachiaria decumbens em resposta ao corte e adubação nitrogenada. Archivos de Zootecnia, v.61, p.91-102, 2012. DOI: 10.4321/S0004-05922012000100010.

DIFANTE, G. dos S.; NASCIMENTO JÚNIOR, D. do; SILVA, S.C. da; EUCLIDES, V.P.B.; MONTAGNER, D.B.; SILVEIRA, M.C.T. da; PENA, K. da S. Características morfogênicas e estruturais do capim-marandu submetido a combinações de alturas e intervalos de corte. Revista Brasileira de Zootecnia, v.40, p.955-963, 2011. DOI: $10.1590 / \mathrm{S} 1516-35982011000500003$.

FERRARO, D.O.; OESTERHELD, M. Effect of defoliation on grass growth: a quantitative review. Oikos, v.98, p.125-133, 2002. DOI: $10.1034 / j .1600-0706.2002 .980113 . x$.

GARCEZ NETO, A.F.; NASCIMENTO JÚNIOR, D. do; REGAZZI, A.J.; FONSECA, D.M. da; MOSQUIM, P.R.; GOBBI,
K.F. Respostas morfogênicas e estruturais de Panicum maximum cv. Mombaça sob diferentes níveis de adubação nitrogenada e alturas de corte. Revista Brasileira de Zootecnia, v.31, p.1890-1900, 2002. DOI: $10.1590 / \mathrm{S} 1516-35982002000800004$

LARA, M.A.S.; PEDREIRA, C.G.S. Respostas morfogênicas e estruturais de dosséis de espécies de braquiária à intensidade de desfolhação. Pesquisa Agropecuária Brasileira, v.46, p.760-767, 2011. DOI: 10.1590/S0100-204X2011000700012.

LEMAIRE, G.; OOSTEROM, E. van; JEUFFROY, M.-H.; GASTAL, F.; MASSIGNAM, A. Crop species present different qualitative types of response to $\mathrm{N}$ deficiency during their vegetative growth. Field Crops Research, v.105, p.253-265, 2008. DOI: 10.1016/j.fcr.2007.10.009.

MAGALHÃES, J.A. Características morfogênicas e estruturais, produção e composição bromatológica de gramíneas forrageiras sob irrigação e adubação. 2010.138p. Tese (Doutorado) Universidade Federal do Ceará, Fortaleza.

PONTES, L. da S.; NABINGER, C.; CARVALHO, P.C. de F.; TRINDADE, J.K. da; MONTARDO, D.P.; SANTOS, R.J. dos. Variáveis morfogênicas e estruturais de azevém anual (Lolium multiflorum Lam.) manejado em diferentes alturas. Revista Brasileira de Zootecnia, v.32, p.814-820, 2003. DOI: 10.1590/ S1516-35982003000400005.

PONTES, L. da S.; LOUAULT, F.; CARRÈRE, P.; MAIRE, V.; ANDEUZA, D.; SOUSSANA, J.F. The role of plant traits under their plasticity in the response of pasture grasses to nutrients and cutting frequency. Annals of Botany, v.105, p.957-965, 2010. DOI: 10.1093/aob/mcq066.

SANTOS, M.E.R.; FONSECA, D.M. da; GOMES, V.M.; SILVA, P.S. da; SILVA, G.P.; CASTRO, M.R.S. e. Correlações entre características morfogênicas e estruturais em pastos de capim-braquiária. Ciência Animal Brasileira, v.13, p.49-56, 2012. DOI: $10.5216 /$ cab.v13i1.13041.

SARMIENTO, G. Adaptive strategies of perennial grasses in South American savannas. Journal of Vegetation Science, v.3, p.325-336, 1992. DOI: $10.2307 / 3235757$.

SILVA, J.S.O.; HARIDASAN, M. Acúmulo de biomassa aérea e concentração de nutrientes em Melinis minutiflora P. Beauv. e gramíneas nativas do cerrado. Revista Brasileira de Botânica, v.30, p.337-344, 2007. DOI: 10.1590/ S0100-84042007000200016.

SIMOES, M.; BARUCH, Z. Responses to simulated herbivory and water stress in two tropical $\mathrm{C}_{4}$ grasses. Oecologia, v.88, p.173-180, 1991. DOI: 10.1007/BF00320808.

Recebido em 5 de setembro de 2012 e aprovado em 22 de fevereiro de 2013

Pesq. agropec. bras., Brasília, v.48, n.3, p.320-328, mar. 2013

DOI: 10.1590/S0100-204X2013000300011 